\title{
Spatial Distribution, Terminology Hotspot and Evolution of Water Resources Research
}

\author{
Li Feng, ${ }^{1,2, ~ a, ~}$, Yang $\mathrm{Hu}^{1, \mathrm{~b}}$ \\ ${ }^{1}$ Business School of Hohai University, \#8 Focheng west road, Jiangning District, Nanjing city, \\ Jiangsu Province, PR China \\ ${ }^{2}$ Library of Hohai University, \#1 Xikang Road, Gulou District, Nanjing city, Jiangsu Province, PR \\ China \\ afengli_tsg@hhu.edu.cn,ㄴ75689208@qq.com \\ *corresponding author: Li Feng
}

Keywords: Water Resources, Research Domain, Spatial Distribution, Evolution, Terminology Hotspot

Abstract: In this paper, based on JCR and SCI paper data,there are 5000 literature data for the study, which come from the ISI Web of Science database included in the field of water resources five representative international journals published in 10 years. Through the CiteSpace software analysis and processing of relevant citation data and keyword data, in the form of knowledge map combing the field of water resources important academic literature and its representative task, The related patterns are generated, knowledge mapping method and citespace software were used to analyze the distribution of research area network, authors' information network, research focus and knowledge base network of the water resource theory research. It shows the regional and research institutions in the field of water resources, the key node literature and the hotspot keywords, the main research orient, etc. Revealing the research power distribution information, knowledge base and research hotspots, and development front of information management disciplines.

\section{Introduction}

Population growth and development are associated with increased water demand that often exceeds the capacity of existing resources, resulting in water shortages, particularly in urban areas, where more than $60 \%$ of the world's population resides.(Constantine and Massoud et al., 2017). Nearly $80 \%$ of the world's population is exposed to high levels of threat to water security. Protecting the world's freshwater resources requires diagnosing threats over a broad range of scales, from global to local. Massive investment in water technology enables rich nations to offset high stressor levels without remedying their underlying causes, whereas less wealthy nations remain vulnerable. (Voeroesmarty and McIntyre et al., 2010) Energy, food, environment and industrial policies of a nation, all of which have intimate linkages to water. Each will affect the other, and, in turn, be affected by the others. Policies in all these areas will be also influenced by exogenous forces such as demographic transitions, advances in technology and information and communication systems, climatic change, globalization, free trade and increasing social activism. 
All these and other associated developments will mean that water management will change more during the next 20 years than in the past 2000 years.(Biswas and Seetharam, 2008)

Water is a basic material condition related to human survival and social development (Ternes, 1998). (Water is a basic material condition related to human survival and social development. At the same time, water resources are a limited and irreplaceable valuable resource, and it is also the basic condition for realizing sustainable economic and social development. Therefore, water resource is related to social development, environmental protection, scientific and technological progress and many other aspects.) Water and air, food is the three elements of human life and health. Water is the source of all life and the environment, both the source of human life and the natural ecological environment of the main factors, through the water in the ecosystem in the cycle, can effectively maintain the natural ecosystem of self-balance(Frolund and Palmgren et al., 1996).(water ,especially fresh water, is one of the most important strategic resources, it plays a significant role in the social development and survival of mankind.) Water is also the lifeline of economic development and social progress and an important material basis for achieving sustainable development (Cirpka and Valocchi, 2016). Whether it is today, or in the future society, water is always indispensable, irreplaceable resources, Humans rely on water and live, relying on water and development, Water to make people alive, promote the birth and development of social civilization, and the evolution of civilization and give the water more glory and Reiki(Arico and Lo $\mathrm{Re}$, 2016). People cannot no water, the ecological environment is inseparable from the water, no water, there is no human society today, more impossible to build a harmonious society. Earth's water resources, in a broad sense, refers to the overall amount of water within the water ring. Including surface water and groundwater controlled by humans and used directly for irrigation, power generation, shipping, aquaculture, etc., as well as rivers, lakes, tides, harbors and aquaculture waters (Sanchez-Vila and Fernandez-Garcia, 2016). In the narrow sense is the year to recover and update the amount of fresh water. Water resource is an important natural resource that is indispensable to the development of the national economy. In many parts of the world, the demand for water has exceeded the level of water resources, while many areas are also on the brink of water resources, Therefore, water resources is related to social development, Environmental protection, scientific and technological progress and many other aspects, we should cherish water resources(Yin and He et al., 2017).

The main fields of water resources research are focusing on the ecological environment, economy, politics, culture and other fields (Wandera and Mallick et al., 2017). In recent years, with the severe shortage of water resources and uneven distribution of water resources and water pollution and other issues highlighted, to strengthen the research and protection of water resources has become consensus for national government departments, hydrology and water conservancy, economic and other scientists (Carballa and Omil et al., 2004). Water resources in terms of use can be divided into ecological water, domestic water, water production, water resources research will change with the direction of the problem, and its subdivision direction is more complex, so you want a comprehensive economy, Environmental, social, political, ecological, cultural and other aspects of water resources research is a complex and huge project (Bailey and Olin et al., 1999). At present, some new directions and research areas have emerged in water resources research (Davis and Volesky et al., 2003). For example, water security and water strategy have attracted increasing attention by related experts, because their significance in the long-term development in all domains (von Gunten, 2003). Specifically, in recent years, with the rapid socio-economic development and the impact of human activities, people unbridled to the nature of the request for plunder, resulting in the emergence of people competing for water, regional and regional competition for water, people and the ecological environment for water, pollutants and ecological environment, such as water and other undesirable phenomena(Muniruzzaman and Rolle, 2016), So that the continuous reduction of 
water resources, increased pollution, weakened or loss of normal water function, cannot maintain its social and economic value, change the balance of hydrological cycle, and reduce water quality, a direct impact on the basic needs of human water, the consequences of this action are recessive, extensive and lagging, When the long-term accumulation of more than bear the threshold, it will endanger the natural environment, the normal operation of the socio-economic system and a virtuous circle, and then lead to a series of water security issues( $\mathrm{Li}$ and Mahendra et al., 2008; Fiori and Cvetkovic et al., 2016).

Through the relevant database site and the actual research, the author and his research team on the international water resources research results which including papers and related professional reviews, in-depth excavation and analysis, The study shows that the research results in the field of international water resources have entered a rapid growth stage in the new century, especially in the past decade. From the national and regional research on the field of water resources attention can be seen, the field of water resources research mainly concentrated in Europe and the United States and other developed countries, research mainly on the comprehensive utilization of water resources and sustainable development issues, while focusing on water resources and Ecological environment, economic interests, social development and other aspects of the relationship between the comprehensive management of a large number of studies. This trend can be seen more and more countries and regions began to pay attention to and study the development of water resources related issues and progress.

Scientific knowledge map is driven by information technology, the recent development of a new field, has now become a new hot spot in science metrology. With the help of scientific knowledge, people can look at the structure of each domain in the huge knowledge system, straighten out the complex knowledge network formed by the contemporary knowledge explosion, and predict the latest development of the forefront of scientific and technological knowledge. This paper uses the scientific visualization map to analyze and analyze the literature on the subject of water resources, and aims at grasping the dynamic process, characteristics and laws of water resources research and development at home and abroad. Attempting to study the status of literature published in the field of water resources at home and abroad through visualization technology, with a view to more comprehensive display of the international water resources development process. In this paper, we use the visual analysis tool of CiteSpace's knowledge map to reveal the status of papers published in the field of international mainstream water resources, To explore the distribution of research institutions in the field of water resources in recent ten years and its knowledge base and research hotspots, And provide reference and reference for the further research of scholars in the field of water resources.

\section{Data and Methods}

\subsection{Journal data}

The data was retrieved on January 1st,2007 to December 12 31th, 2016 from the Science Citation Index-Expanded database and Social Science Citation Index with an online version published by Thomson Reuters. Five journals with the top high rankings in the field of water resources were retrieved from the database in this research with totally 5000 . As seen in Table 1 , there are five journals with an Impact Factor (IF) on the research area of water resources, which belongs to authority journals. These five journals and the influencing factors of journals are "Water research(6.942)", " Desalination (5.527)", ”Advances in water resources (3.221)", "Hydrology and earth system sciences (4.437)", " Water resources research (4.397)”. In table 1, authority journals in water resources area from Web of Science are used to investigate the present and future development trends. 
Table 1 Basic information on five top water resources journals

\begin{tabular}{ccccc}
\hline Serial & Journal title & $\begin{array}{c}\text { Publishing } \\
\text { cycle }\end{array}$ & Country & Publishing agency \\
\hline 1 & Water research & Fortnightly & England & $\begin{array}{c}\text { Pergamon-elsevier science } \\
\text { LTD }\end{array}$ \\
2 & Desalination & Fortnightly & Netherlands & Elsevier science BV \\
3 & $\begin{array}{c}\text { Advances in water } \\
\text { resources }\end{array}$ & Monthly & England & Elsevier sci LTD \\
4 & $\begin{array}{c}\text { Hydrology and earth } \\
\text { system sciences }\end{array}$ & Monthly & Germany & Copernicus gesellschaft MBH \\
5 & Water resources research & Monthly & America & Amer geophysical union \\
\hline
\end{tabular}

\subsection{Methods}

Scientometric analysis is considered as a useful mathematical and statistical method to describe productivity of science, technology and the development trend of research, and can evaluate and predict the relative research will geographic variation in outputs and findings usually. The statistical analysis tool if the Thomson Data Analyzer (TDA); the drawing tool is ArcGIS, CiteSpace4.5 and MS Office Excel 2016. In this scientometrics study, the paper general description, spatial distribution, knowledge base, cited authors and research hotspot were deeply discussed in the quantitative analysis methods.

\section{3 General description}

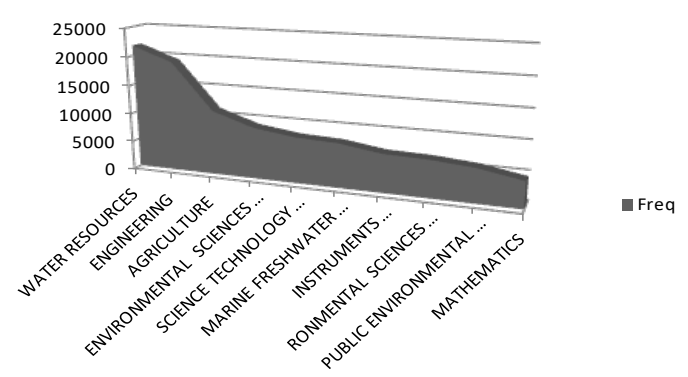

Figure 1. Research direction of water resources journals from 2007 to 2016

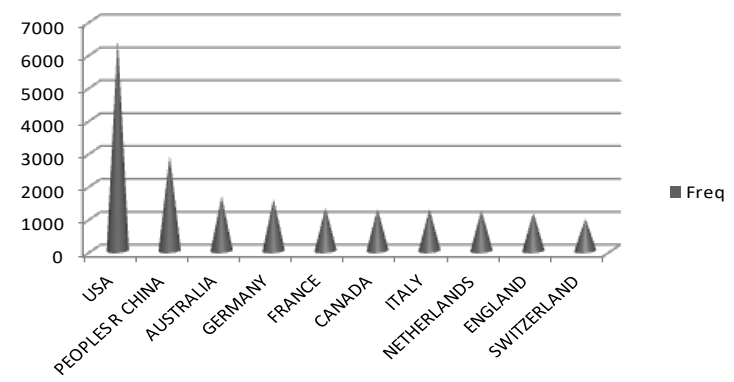

Figure 2 Country distribution of water resources area 2007 to 2016 


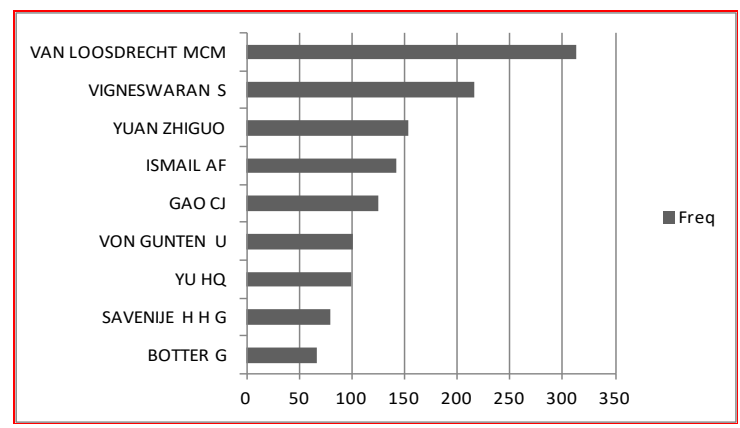

Figure 3. Top publications authors in water resources area journal from 2007 to 2016

Figure1, Figure 2 and Figure 3 reveal the publication output of water resources area research from directions, countries and authors aspects respectively. As Figure 1 shows, 21,777 papers are listed as water resources, 19,269 papers are engineering, 11,259 papers are agricultural science, 8,966 papers are environmental science and ecological science, as well as 7,691 papers are marine freshwater biology. Those five most popular research directions could reflect the classification of this area. Even in those multi-directions, "water resources" remained a dominant research direction in this field. It could be expected that a higher percentage of water resources would be used because most papers listed in this field are published as cross-domain.

From the national statistics issued by the country (in Figure 2), The United States, China, Australia in 2006-2017 issued 6443,2897,1647 papers respectively, which are the top largest number of issued countries. From publication authors statistics (in Figure 3), VAN LOOSDRECHT MCM, VIGNESWARAN S, YUAN ZHIGUO published 313,220,153 academic achievements with the highest ranking. In this research, each journal covered by the highest 1000 cited frequency papers during 2007 to 2016 were selected, totally 5000 papers in this five journals used as research data.

\section{Analysis and discussion}

\subsection{Analysis of Spatial Distribution of Water Resources Papers}

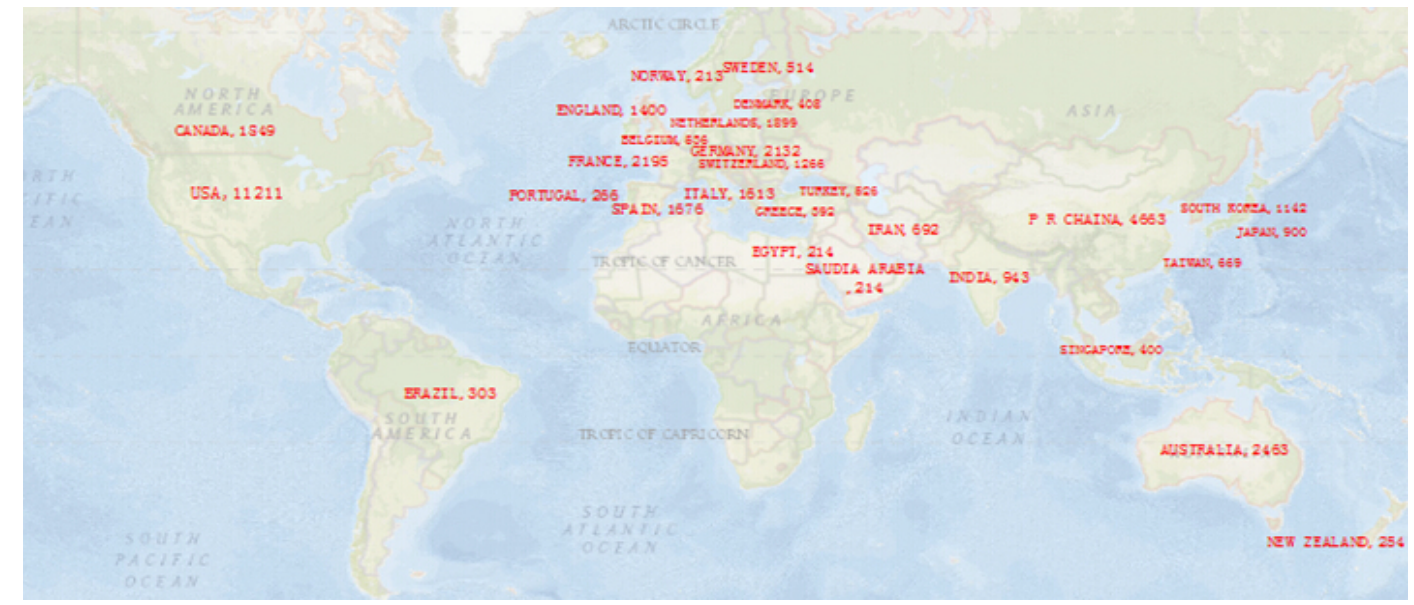

Figure 4 Spatial e distribution of water resources papers 


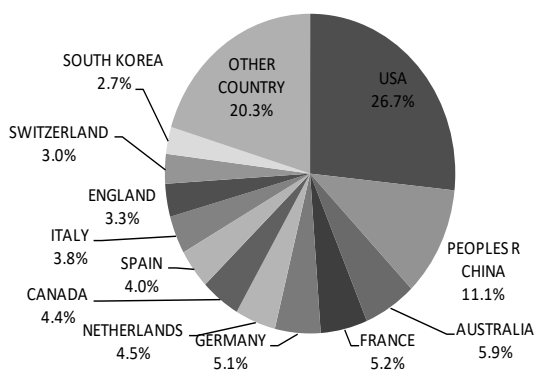

Figure 5 Country Distribution in the Field of Water Resources Research

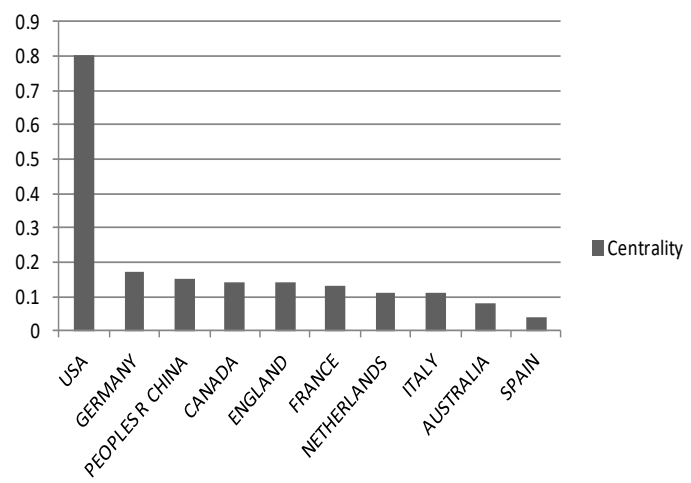

Figure 6 Centrality analysis

As shown in Figure 4, the clustering cluster with USA as the center is most obvious, indicating that the United States in the field of water resources published important journals in the results of the contribution and impact of the most prominent. By elaborating the contribution distribution of each country (in Figure 5) (less than 1,000 countries of the study literature are nationalized as other countries), it can be seen that, in the past decade, the proportion of US papers published in representative journals of water resources and related fields was $26.7 \%$, much higher than that of other countries, indicating that the US government and its various institutions pay more attention to water resources research. By contrast, the next influential countries are China, Australia, France, Germany, the Netherlands, Canada, Spain, Italy, the United Kingdom, it can be seen, in addition to China, ranked in the top ten are developed Western countries.

From figure 5 we can see, only the top ten countries contribute more than $70 \%$, which shows that the field of water resources into the new century, the development stage, the mainstream is still concentrated in Europe and the United States and other developed countries. In the cluster picture, the United States in addition to the number of contributions in the literature, the node center is also the largest, this suggests that other countries or institutions in the field of research in the field of water resources management have more or less cooperative or other links with American studies. For example, in Figure 4, China, Britain, Switzerland and other cooperation with the United States to study more closely. We analyzed the number of documents issued in the top ten countries of the node center we can see,in Figure 6, Germany, China, Canada, the center of the node points out two to four, and its degree of contribution is not consistent, for example, Germany in the past decade the amount of 2132 articles, ranked fifth, but the node center in the forefront, indicating that the field of water resources research more profound, with high impact. 


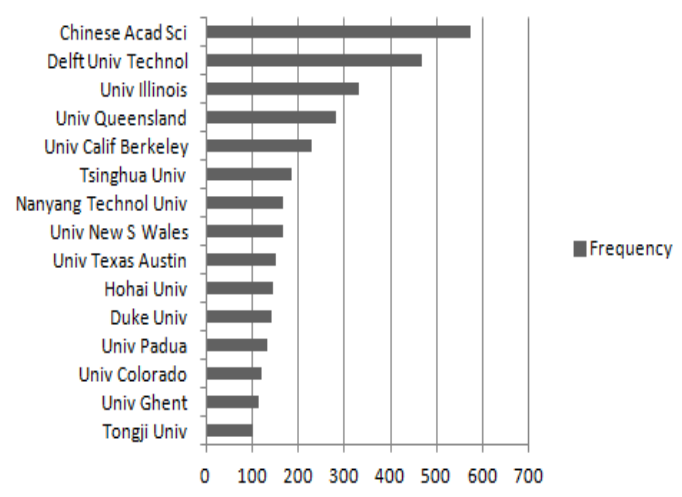

Figure 7 Analysis of the Presentation Situation of Research Institutions

From figure 7, in the field of water resources research institutions, the Chinese Academy of Sciences of the comprehensive strength of the most prominent, leading other foreign institutions, In addition, Tsinghua University, Tongji University, Hohai University as China's water resources research important support. The United States as the paper production and influence are the largest countries, the research institutions are more concentrated in scientific research institutions, in the number of documents issued in the top 15 institutions, Among them, one-third from the United States, Univ Illinois, Univ Calif Berkeley, Univ Texas Austin, Duke Univ, Univ Illinois, Univ California Berkeley, Univ Illinois, In addition the University of Colorado also has a certain scientific research strength. Higher education in the study of water resources, the Netherlands Delft Univ Technol (Delft Univ Technol) the most powerful, which also reflects the Netherlands in the water conservancy management research firm strength, Wageningen Univ, one of the $14 \mathrm{U}$ universities in the Netherlands, has also made an outstanding contribution to the development of water-saving agriculture and water-saving applications. Australia's Queensland Polytechnic University (Univ Queensland) in the water conservancy project research level is relatively strong, Italy's Univ Padua and Univ New S Wales are the oldest university representatives and have their own research in the field of hydrology and water resources. In addition, Germany, France, Denmark, the Netherlands, South Korea, also have a strong strength of the research institutions, water resources research has become an important representative of the field.

\subsection{Analysis of the knowledge base, cited authors and research hotspot in the field of water resources}

Drawing a total of cited network maps is an important way for CiteSpace to demonstrate the subject knowledge and research focus. The network node selects the cited reference and the other selection policies remain unchanged, runing citespace to obtain a total of cited data from the field of water resources research, which enables users to visualize the knowledge domain of water resources and analyze the evolutionary relationship between research hotspot and knowledge base.

\subsubsection{Analysis of knowledge base in the field of water resources}

From the above figure 8, we can understand the knowledge base of the field of water resources research, that is, the important key node literature situation. The concept of the frontier of the study was first proposed by American scholar Price, used to describe the dynamic nature of the field of research. He argues that the frontiers of a field are reflected in articles that are actively cited by scholars in this field. And the knowledge base is generally relative to the concept of the frontier of the research put forward, that is quoted foreword vocabulary related literature citation and its 
co-cited network trajectory. The general subject knowledge analysis can be divided into two parts: early classical literature analysis and key node literature analysis. Due to the particularity of the academic literature in the field of water resources, that is, the field of water resources research is biased towards practical engineering operation, and no corresponding academic literature has been formed in the early stage, In view of this, we only for a total of cited network of water resources in the field of key node literature for a detailed analysis.

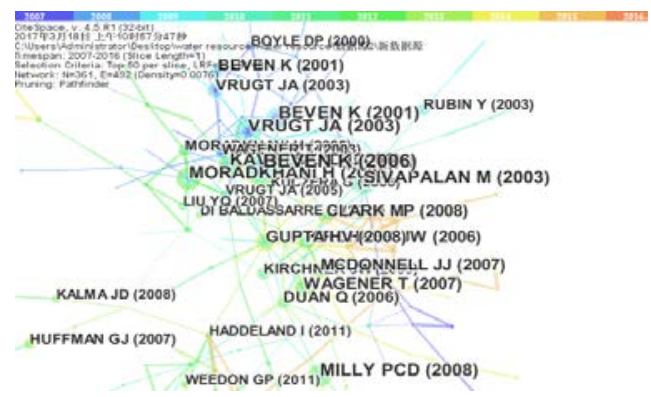

Figure 8. Time zone map of key references in the field of water resources

Table 2 Key node literature information of Water resources

\begin{tabular}{cccccc}
\hline Serial & Author & Journal & Year & Certrality & Freq \\
\hline 1 & GUPTA HV & Hydrological processes & 2008 & 0.27 & 59 \\
2 & BEVEN K & Journal of hydrology & 2006 & 0.19 & 165 \\
3 & MCDONNELL JJ & Water resources research & 2007 & 0.15 & 78 \\
4 & WAGENER T & Geography compass & 2007 & 0.14 & 62 \\
5 & VRUGT JA & Water resources research & 2003 & 0.13 & 104 \\
6 & CLARK MP & Water resources research & 2008 & 0.07 & 62 \\
7 & KIRCHNER JW & Water resources research & 2006 & 0.07 & 54 \\
8 & BEVEN K & Journal of hydrology & 2001 & 0.05 & 96 \\
9 & MILLY PCD & Science & 2008 & 0.05 & 86 \\
10 & VRUGT JA & Water resources research & 2003 & 0.05 & 64 \\
\hline
\end{tabular}

The formation of the key node literature is derived from the development of the knowledge base and the frontier of the research. It is a core document of the field which has been developed in the field of research with the development of time. Center degrees can not only be used to measure the core literature and other literature links, but also represents the ability of the core literature to control or influence other documents. From the figure 8, we can see that each central node represents an article, according to the size of the node (the frequency of the literature cited) and the size of the center of the node (the importance of the literature) to conduct a comprehensive statistics, listed in the literature listed above (as shown in Table 2), Which is cited less than 50 times the article is no longer elaborated. What is needed here is that the total cited frequency is only for the 5000 literature data studied in this paper, and does not represent all the cited frequencies of the literature.

As can be seen from Table 2, the center is ranked first in the article entitled "Reconciling theory with observations: elements of a diagnostic approach to model evaluation" published by GUPTA $\mathrm{HV}$ in the Hydrological processes issue in 2008 (Gupta and Wagener et al., 2008). The central degree of this article is 0.27 , which is 59 times, which mainly discusses the importance of the model construction for the complex research in the modern environment. Under the uncertain conditions of constructing the model, the observation data need to be used to test the model insufficient. The method of evaluating the theory is used to diagnose the shortcomings of the model evaluation method. The method is rooted in the information theory and can be placed in Bayesian reasoning, 
and can also be applied to evaluate the problem in order to analyze the uncertainty. In the second place is BEVEN K published in 2006 papers Assimilation of enterprise systems: The effect of institutional pressures and the mediating role of top management (Beven, 2006). The center of the article is 0.19 , the total cited frequency is up to 165 times. This paper mainly discusses some problems in the prediction and identification of hydrological models under the condition of given some calibration data, and discusses the reason why the traditional hydrological model calibration method is not complete. Therefore, this paper is concerned with a number of acceptable hydrological environment system models to make a more perfect consideration, on the basis of some of the proposed extension of the GLUE method of technology, the model is more rational. The third issue of MCDONNELL JJ in 2007 published in the Water resources research article "Moving beyond heterogeneity and process complexity: A new vision for watershed hydrology"(McDonnell and Sivapalan et al., 2007), were cited frequency of 78 times, the main research basin hydrology and water resources The scientific progress. Due to the different hydrological and climatic conditions and the heterogeneity and complexity of rainfall runoff at different scales, the study of hydrological watersheds needs to be combined with many watersheds. In order to make progress in watershed hydrology, Heterogeneity, through the use of comparative analysis, classification, optimal principles and network management to study watershed science, forecast watershed function and elucidate the function of important watersheds. The fourth of WAGENER T published in 2007 Catchment Classification and Hydrologic Similarity w, were cited frequency of 62 times, mainly to study the classification of catchment and its hydrological similarity. According to the classification system of hydrological watershed, the author mainly makes three tasks: (1) review existing methods to define hydrological similarity and watershed classification; (2) discuss unresolved features in the classification framework; (3) provide the basic framework for watershed classification. Suggest and discuss possible measures to describe the form, hydrological climate and function. The "A Shuffled Complex Evolution Metropolis algorithm for optimization and uncertainty assessment of hydrologic model parameters" published by the VRUGT JA at the fifth in 2003 in the Water resources research (Vrugt and Dekker et al., 2003), This paper deals with the optimization of the hydrological model parameters and the uncertainty evaluation algorithm. A Markov chain Monte Carlo (MCMC) sampler is proposed and proposed for estimating the posterior distribution of hydrological model parameters.

In general, the above cited key node literature reflects the common ground in the field of water resources research, specifically embodied in the following aspects: (1) the study of water resources problems are usually accompanied by a large number of data, different environments reflect the problem of data is also different, the data has features that include heterogeneity and complexity; (2) Evaluating objects and research data with hydrological or water resources needs to be assisted by mathematical models, and the results of the analysis are constantly calibrated and optimized due to the limitations of the model; (3) Due to the complexity of hydrological and climatic conditions, the study of river basin water resources is usually studied by means of comprehensive comparison of several watersheds.

\subsubsection{Analysis of the cited authors in the field of water resources}

The author presents a map showing the relevant representatives of water resources research and the highly influential papers (as shown in Figure 8). Such as BEVEN K (2000, 2001, 2006, 2010), VRUGT JA (2003, 2005, 2008, 2010), WAGENER T (2001, 2003, 2007, 2010), KIRCHNER JW (2000, 2003, 2006, 2009), CLARK MP (2008, 2011), GUPTA HV (2008, 2012), and the like. It can be seen from that BEVEN K has published five articles in the field of water resources in SCI, in which the number of citations of the two articles in this paper is 165 times, 96 times, he's the most influential author of the field of water resources research. And he is a research scholar in the field of 
water resources at the University of Lancaster, UK. His representative papers are: A manifesto for the equifinality thesis and Equifinality, data assimilation, and, uncertainty estimation in mechanistic modeling of complex environmental systems using the GLUE methodology. These two papers mainly study the application of the forecasting model in the hydrological environment system and the river runoff simulation system. Prof. VRUGT JA from the University of Amsterdam's Univ Amsterdam Biodiversity and Ecosystem Research Institute has a strong influence in the field of water resources research. He focuses on the theoretical methods and principles of ecological diversity of water resources. To be in the field of water resources international professional journals have five papers in the SCI was cited, There are A Shuffled Complex Evolution Metropolis algorithm for optimization and uncertainty assessment of hydrologic model parameters, and, Effective and efficient algorithm for multi-objective optimization of hydrologic models and Identification of rainfall interception model parameters from measurements of throughfall and forest canopy storage, mainly study the parameter design of hydrological model and its optimization algorithm in practical application(Vrugt and Gupta et al., 2003; Vrugt and Gupta et al., 2003).WAGENER T, a scholar of the University of Arizona's Water Conservancy and Hydropower Institute, published several papers on waterOL journals such as HYDROL EARTH SYST SC, HYDROL PROCESS, GEOGRAPHY COMPASS, mainly study the rainfall runoff model, hydrological and water resources development prospects and so on.

From the above-mentioned representative of the high cited authors of the research results can be seen, the study of water resources mainly from three aspects: (1) study the basic theory and methods of water resources, including water resources and environment, water resources ecology, water economy and other areas of water resources derived from the direction; (2) study the specific application of water resources forecasting model, including in hydrology, watersheds, oceans and other aspects of the application; (3) The combination of theory and application of water resources field, that is, through the basic theory and method of research, and constantly adjust the use of water resources forecasting model, the research results more standardized.

\subsubsection{Analysis of research hotspot in the field of water resources}

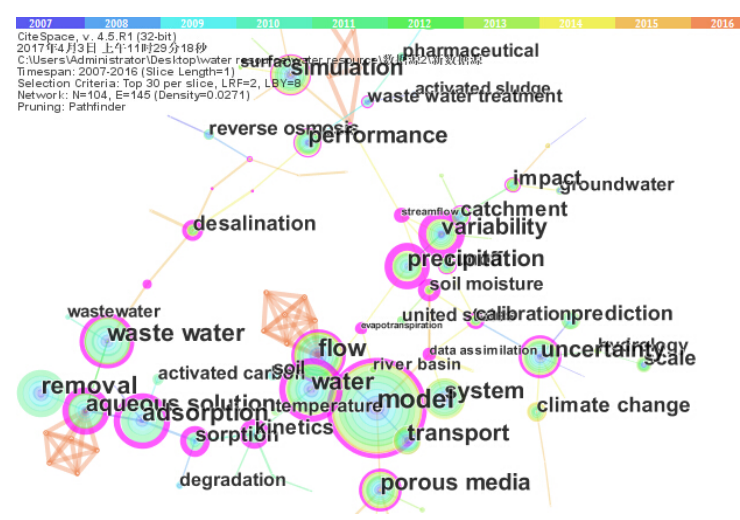

Figure 9. Map of hot topics in the field of water resources

Key words can effectively reflect the focus of research in a paper, the co-occurrence of key words is an analysis based on text content analysis method, CiteSpace software analysis keywords are common from the cited literature extracted from the high-frequency keywords, and high-frequency keywords can represent the field of research hot spots. The number of co-occurrence shows the number of keywords extracted from the cited literature, which can be interpreted as a research hotspot, Therefore, the analysis of hotspot keywords can effectively obtain the research hotspots in the current research field. A centimeter is a node that has a critical role in the network. This indicator reflects the node in the entire network of influence, that is, the ability to 
affect other nodes. The main indicators of the study are the co-occurrence frequency of the keywords and the corresponding center of the nodes. Adjust the relevant threshold, we get the water resources in the field of co-occurrence map (shown in Figure 9).

From the map we contemputer out the frequency of a higher keyword, The frequency of the "Model" and "Water" were 619 and 365, respectively, and the Centrality were 0.14 and 0.35 respectively. Water is the main research object in the field of water resources, the construction of model is an important tool to study water problem, This shows that the "water" and "model" in the field of water resources in the highest degree of importance, but also from the side to reflect the international scope of the field of water resources and published on the subject of the article, it shows that the mainstream of water resources research is closely related to the construction of related water model. At the same time, it explains the essence of water resources problem, that is, the quantitative calculation of water resources related problems through the construction of technical model, so as to arrange the project progress reasonably. Through the frequency analysis of key words, the main hotspots in water resources research are: "Flow", "Waste", "System", "Simulation”, "Porous media”, "Uncertainty”, "Drinking water", “desalination”, and so on. We listed the frequency of 70 and above the key words (as shown in Table 3), the mainstream of these areas of water resources research topics mainly related to engineering construction, system simulation, industrial technology, social life and so on.

Table 3 High - frequency keywords in related literature in the field of water resources

\begin{tabular}{|c|c|c|c|c|c|c|c|}
\hline Freq & Certrality & Year & Keywords & Freq & Certrality & Year & Keywords \\
\hline 619 & 0.14 & 2007 & model & 145 & 0.01 & 2007 & catchment \\
\hline 365 & 0.35 & 2007 & water & 145 & 0.08 & 2007 & climate change \\
\hline 349 & 0.34 & 2007 & flow & 142 & 0.03 & 2007 & prediction \\
\hline 330 & 0.14 & 2007 & waste water & 141 & 0.07 & 2008 & kinetics \\
\hline 298 & 0.09 & 2007 & system & 131 & 0.05 & 2008 & impact \\
\hline 287 & 0.22 & 2007 & simulation & 115 & 0.15 & 2008 & desalination \\
\hline 277 & 0.26 & 2007 & porous media & 107 & 0.06 & 2008 & runoff \\
\hline 260 & 0.22 & 2007 & uncertainty & 91 & 0.14 & 2007 & $\begin{array}{l}\text { reverse } \\
\text { osmosis }\end{array}$ \\
\hline 209 & 0.18 & 2007 & variability & 85 & 0.01 & 2009 & pharmaceutical \\
\hline 206 & 0.12 & 2007 & $\begin{array}{c}\text { drinking } \\
\text { water }\end{array}$ & 72 & 0.01 & 2011 & united states \\
\hline 202 & 0.27 & 2007 & performance & 70 & 0.01 & 2007 & degradation \\
\hline
\end{tabular}

\subsection{Analysis of evolution in the field of water resources}

Through the analysis of the latest research directions in the field of water resources, we can grasp the research progress and evolution of the current water resources field, and provide the reference direction for the future development of the field.

The research object of this paper comes from the ISI Web of Science database included in the field of water resources five representative international journals published in 10 years. The research team surveyed the development of water resources in representative countries on all continents, including China, Japan, Indonesia, US, Brazil, Russia, England, Germany, Egypt. We also surveyed the global climate conference and some other international conferences on the latest developments in water resources development, and background of the world economy, politics, environment, society, ecological development environment. Combined with the ISI Web of Science database analysis and Citespace in the outbreak of the emergence of the word analysis, We 
summarize and analyze the evolution of the development of water resources (shown in Figure 10).

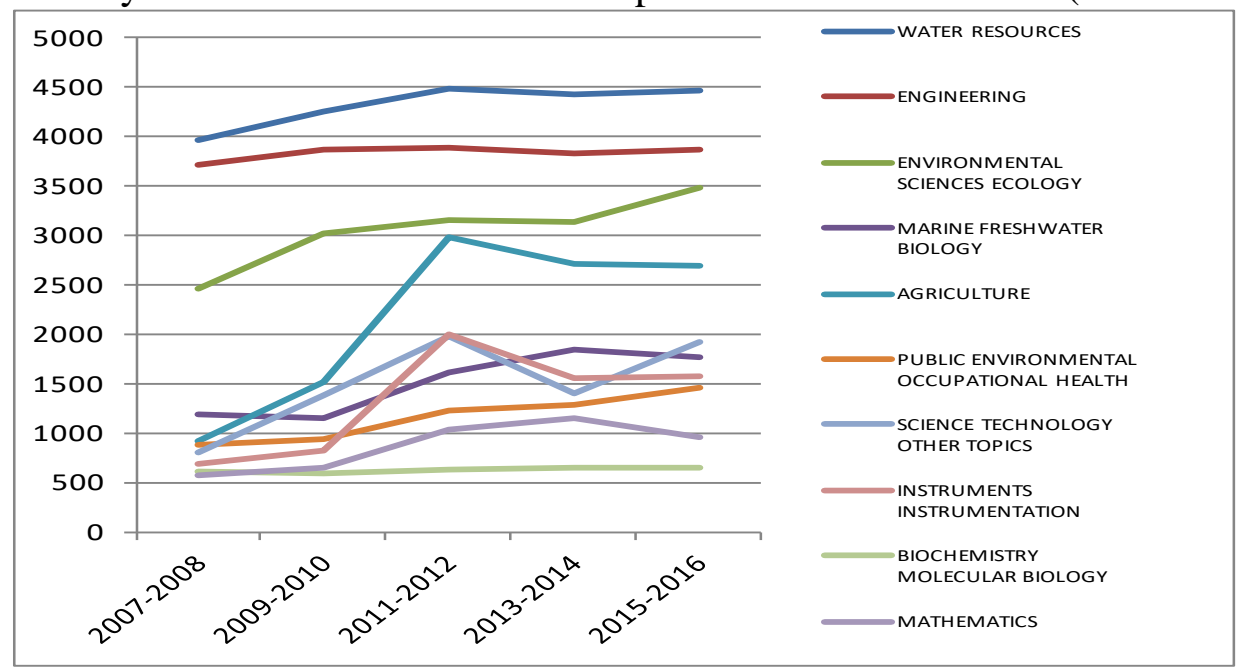

Figure 10 Evolution in the field of water resources

From the above figure 10, In the literature on the publication of five representative journals in the field of water resources in the decade of 2007-2016, we can understand that agricultural research direction of the literature of the most obvious changes in the trend, the overall trend of rising, indicating that with the increase in the global population, in the field of agricultural water resources research has been more and more attention, And related agricultural irrigation water, agricultural water conservancy projects and other important branches have become the focus of research in recent years.

In addition, the trend of environmental science ecology, instruments instrumentation and science technology other topics, is also more obvious. On the one hand, with the global economic development brought about by a series of environmental problems caused widespread concern, and the environment is closely related to the field of water resources is no exception, over the past decade, the literature on environmental science published in the field of water resources has been increasing year by year.

On the other hand, with the integration of water resources and engineering technology, the promotion of water resources research more and more dependent on accurate scientific data, which in turn can not do without the relevant instrument accurate measurement and display, so the instruments instrumentation as the direction of water resources research has been the industry scholars generally concerned. With the study of the field of water resources has also been a variety of other interdisciplinary impact, so the science technology other topics research fluctuations are more obvious.

Other directions, such as water resources, engineering, public environmental occupational health, mathematics and other research directions has always been the subject of research in the field of water resources, and the trend of the relevant literature shows a steady upward trend.

\section{Conclusion}

In this paper, the water resources field as the research object, collected ISI Web of Science database in the representative of the five kinds of water resources in the field of high impact factor journals in 2007 - 2016 included in the literature, According to the paper cited the situation select 5000 literature data as a data source, the use of visual analysis software CiteSpace 4.5 statistics and analysis, generated by the relevant knowledge map shows national and institutional distribution, knowledge base and research hotspot, academic representative of the international water resources 
research. Get the following conclusions:

First, from the field of water resources research geographical distribution map, the Chinese Academy of Sciences in the field of water resources research results in the first of all institutions, indicating that China's scientific research in the field of water issues of great concern and have the ability to study a variety of water issues, while at the same time, Tsinghua University, Tongji University, Hohai University and other Chinese water conservancy research institutions of higher learning have also made important contributions. But for the country, the United States is the largest contributor to the output and influence of the paper in the field of water resources, and its research institutions are also most distributed, indicating that the development of the United States in this field is ahead of other countries. In addition, China, the Netherlands, Canada and other countries is also an important force in the field of research. Second, from the analysis of the total cited literature, demonstrating the core literature that has evolved with the continuous development of research, And lists five articles, their center ranked in the forefront and were cited in the frequency of more than 50. In addition, from the cited literature, analysis of the international water resources in the field of concern and attention to the study of mainstream vocabulary, By studying the high frequency and the high hotspot keywords in the center, We come to the mainstream of the field of water resources research mainly related to engineering construction, system simulation, industrial technology, social life and other aspects. Thirdly, research front in the field of water resources research, which has had a profound impact on the progress of water resources research in different aspects. Involving fresh water, irrigation water, waste water recycling, industrial water, water ecology, water economy, microbiology, water environment, agricultural water conservancy, new energy, hydrology, marine freshwater biology, oceanography, desalination. The research direction of these water resources areas is constantly explored and developed, reflecting the forefront of the field of water resources research. Finally, the research data of this paper only comes from the five kinds of journals whose sources are directly related to the field of water resources, and there are some limitations in the depth of the research, In the future study needs to be improved and amended.

\section{Acknowledgments}

This work was supported by the National Natural Science Foundation of China, No. 71503068 and 71603075; National Philosophy and Social Science Fund Key Grant, No.16AGL005 and No. 11\&ZD168.

\section{References}

[1] Arico, C. and C. Lo Re (2016). "A non-hydrostatic pressure distribution solver for the nonlinear shallow water equations over irregular topography." ADVANCES IN WATER RESOURCES 98: 47-69.

[2] Bailey, S. E. and T. J. Olin, et al. (1999). "A review of potentially low-cost sorbents for heavy metals." WATER RESEARCH 33 (11): 2469-2479.

[3] Beven, K. (2006). "A manifesto for the equifinality thesis." JOURNAL OF HYDROLOGY 320 (1-2SI): 18-36.

[4] Biswas, A. K. and K. E. Seetharam (2008). "Achieving water security for Asia." INTERNATIONAL JOURNAL OF WATER RESOURCES DEVELOPMENT 24 (1): 145-176.

[5] Carballa, M. and F. Omil, et al. (2004). "Behavior of pharmaceuticals, cosmetics and hormones in a sewage treatment plant." WATER RESEARCH 38 (12): 2918-2926.

[6] Cirpka, O. A. and A. J. Valocchi (2016). "Debates-Stochastic subsurface hydrology from theory to practice: Does stochastic subsurface hydrology help solving practical problems of contaminant hydrogeology?" WATER RESOURCES RESEARCH 52 (12): 9218-9227.

[7] Constantine, K. and M. Massoud, et al. (2017). "The role of the water tankers market in water stressed semi-arid urban areas:Implications on water quality and economic burden." JOURNAL OF ENVIRONMENTAL MANAGEMENT 188: $85-94$. 
[8] Davis, T. A. and B. Volesky, et al. (2003). "A review of the biochemistry of heavy metal biosorption by brown algae." WATER RESEARCH 37 (18): 4311-4330.

[9] Fiori, A. and V. Cvetkovic, et al. (2016). "Debates-Stochastic subsurface hydrology from theory to practice: The relevance of stochastic subsurface hydrology to practical problems of contaminant transport and remediation. What is characterization and stochastic theory good for?" WATER RESOURCES RESEARCH 52 (12): 9228-9234.

[10] Frolund, B. and R. Palmgren, et al. (1996). "Extraction of extracellular polymers from activated sludge using a cation exchange resin." WATER RESEARCH 30 (8): 1749-1758.

[11] Gupta, H. V. and T. Wagener, et al. (2008). Reconciling theory with observations: elements of a diagnostic approach to model evaluation.

[12] Li, Q. and S. Mahendra, et al. (2008). "Antimicrobial nanomaterials for water disinfection and microbial control: Potential applications and implications." WATER RESEARCH 42 (18): 4591-4602.

[13] McDonnell, J. J. and M. Sivapalan, et al. (2007). "Moving beyond heterogeneity and process complexity: A new vision for watershed hydrology." WATER RESOURCES RESEARCH 43 (W073017).

[14] Muniruzzaman, M. and M. Rolle (2016). "Modeling multicomponent ionic transport in groundwater with IPhreeqc coupling: Electrostatic interactions and geochemical reactions in homogeneous and heterogeneous domains." ADVANCES IN WATER RESOURCES 98: 1-15.

[15] Sanchez-Vila, X. and D. Fernandez-Garcia (2016). "Debates-Stochastic subsurface hydrology from theory to practice: Why stochastic modeling has not yet permeated into practitioners?" WATER RESOURCES RESEARCH 52 (12): 9246-9258.

[16] Ternes, T. A. (1998). "Occurrence of drugs in German sewage treatment plants and rivers." WATER RESEARCH 32 (11): 3245-3260.

[17] Voeroesmarty, C. J. and P. B. McIntyre, et al. (2010). "Global threats to human water security and river biodiversity." NATURE 467 (7315): 555-561.

[18] von Gunten, U. (2003). "Ozonation of drinking water: Part I. Oxidation kinetics and product formation." WATER RESEARCH 37 (PII S0043-1354(02)00457-87): 1443-1467.

[19] Vrugt, J. A. and H. V. Gupta, et al. (2003). "A Shuffled Complex Evolution Metropolis algorithm for optimization and uncertainty assessment of hydrologic model parameters." WATER RESOURCES RESEARCH 39 (12018).

[20] Vrugt, J. A. and H. V. Gupta, et al. (2003). "Effective and efficient algorithm for multiobjective optimization of hydrologic models." WATER RESOURCES RESEARCH 39 (12148).

[21] Vrugt, J. A. and S. C. Dekker, et al. (2003). "Identification of rainfall interception model parameters from measurements of throughfall and forest canopy storage." WATER RESOURCES RESEARCH 39 (12519).

[22] Wandera, L. and K. Mallick, et al. (2017). "Upscaling instantaneous to daily evapotranspiration using modelled daily shortwave radiation for remote sensing applications: an artificial neural network approach." HYDROLOGY AND EARTH SYSTEM SCIENCES 21 (1): 197-215.

[23] Yin, J. and F. He, et al. (2017). "Effects of land use/land cover and climate changes on surface runoff in a semi-humid and semi-arid transition zone in northwest China." HYDROLOGY AND EARTH SYSTEM SCIENCES 21 (1): 183-196. 